\title{
Serotonin and the aversive threshold in rats*
}

\author{
VINCENT P. HOUSER and DALE A. VAN HART $\dagger^{\dagger}$ \\ Psychotropic Drug Laboratory, VA Hospital, Perry Point, Maryland 21902
}

\begin{abstract}
The present study explored the effects of p-chlorophenylalaline (p-CPA-300, 200, 100,50 mg/kg) and 5-hydroxy tryptophan (5-HTP-15, 40,60,70,95,125,175 $\mathrm{mg} / \mathrm{kg})$ upon the aversive threshold of the rat using the spatial preference technique. p-CPA had no reliable effects on the aversive threshold or upon motor activity as measured by this technique. 5-HTP, on the other hand, significantly raised the aversive threshold to moderate levels under the $95-$ and $125-\mathrm{mg} / \mathrm{kg}$ dosages, while motor activity was reduced under the $60-, 70-, 95-$ and $125-\mathrm{mg} / \mathrm{kg}$ dosages. p-CPA $(200 \mathrm{mg} / \mathrm{kg})$ was able to block both the increased thresholds and reduced motor activity noted after $125 \mathrm{mg} / \mathrm{kg}$ of $5-\mathrm{HTP}$. These results were interpreted to suggest that modulation of serotonergic activity has little effect upon the aversive threshold of the rat.
\end{abstract}

Serotonin has been implicated as one brain amine that may play a significant role in altering pain sensitivity in a number of animal species. For example, Tenen (1967) has reported that the administration of p-chlorophenylalanine, a serotonin depleting agent, to rats leads to a reduction in the pain threshold as measured by the flinch-jump method. Other evidence (Lee \& Fennessy, 1970) has suggested that there is a correlation between morphine-induced analgesia and reduced levels of serotonin in the mouse brain Furthermore, it has been reported that p-chlorophenylalanine (p-CPA) antagonizes the analgesic effects of morphine (Fennessy \& Lee, 1970; Tenen, 1968). These findings have led Tenen (1968) to suggest that morphine analgesia is mediated by the release of serotonin.

All the above data is consistent with the hypothesis that reductions in serotonergic activity, via the administration of $\mathrm{p}$-CPA, leads to a reduction in the pain threshold, while elevations in serotonergic activity may produce analgesia. Although this simplistic model is attractive, other evidence suggests that serotonergic systems may have contrasting effects upon behavior acquired in the presence of electric shock. Stein, Wise, and Berger (1973) have presented data which suggest that a serotonergic system may mediate the behaviorally suppressive effects of punishment (i.e., usually electric shock). Support for this concept is found in a report by Geller and Blum (1970) who note that p-CPA attenuated the suppression of barpressing behavior normally noted when each response was paired with a brief electric shock. These results are difficult to interpret if one assumes that p-CPA lowers the pain threshold for electric shock.

The above contrasting evidence suggests that the

*All requests for reprints should be sent to the senior author at the Psychotropic Drug Laboratory, VA Hospital, Perry Point, Maryland 21902.

tThe authors wish to express their appreciation to Luther $R$. Gilliam of the Medical Illustration Service, VA Hospital, Perry Point, Maryland, for performing the photographic work. Thanks are also due to Randall J. Cash and Richard L. Seiser for their excellent technical assistance in gathering the data. effects of manipulating serotonergic tone upon pain sensitivity are far from clear. The present report is an attempt to explore the effects of p-CPA and 5-hydroxytryptophan, a precursor of serotonin, upon the aversive threshold of rats using the spatial preference technique. This technique has proven to be an extremely sensitive and reliable measure of drug-induced analgesia reacting to a host of agents known to be clinically active in man [e.g., morphine (Houser \& Paré, 1972), pentazocine, cyclazocine (Houser \& Paré, 1973a), and sodium salicylate (Houser \& Paré, 1973b)]. Thus, by utilizing this technique, the present report may supply more definitive evidence as to whether serotonin plays a role in mediating the aversive qualities of electric shock.

\section{METHOD}

\section{Subjects}

Twelve male Sprague-Dawley derived rats obtained from ARS/Sprague-Dawley, Madison, Wisconsin, were used in the present study. They weighed $286-321 \mathrm{~g}$ at the beginning of the experiment.

\section{Apparatus}

The test chamber and apparatus have been described in detail elsewhere (Hou ser \& Paré, 1972). Briefly, the chamber consisted of a rectangular Plexiglas shuttlebox which was pivoted in the middle, allowing the box to tilt from side to side as the animal crossed from one end to the other. This tilting movement activated a light-action Acro leverswitch located at one end of the cage which controlled the presentation of shock. The stainless steel rods which formed the floor of the cage could be electrified by various intensities of shock. The shock stimulus was provided by a dc generator which produced a $60-\mathrm{Hz}$ square wave ou tput (Reus, Houser, \& Paré, 1971).

\section{Procedure}

Each animal was subjected to a 50-min experimental session, the same time each day, 6 days a week. An experimental session consisted of five $10-\mathrm{min}$ periods in which five separate current intensities (i.e., 30, 60, 90,120,150, microA) were presented in an ascending order. The shock was presented continuously on one side of the cage for $5 \mathrm{~min}$ and then switched to the other side for the remaining $5 \mathrm{~min}$ of each current intensity. The animal could escape the shock side of the cage by merely crossing to the opposite or nonshock portion of the tilt cage. 


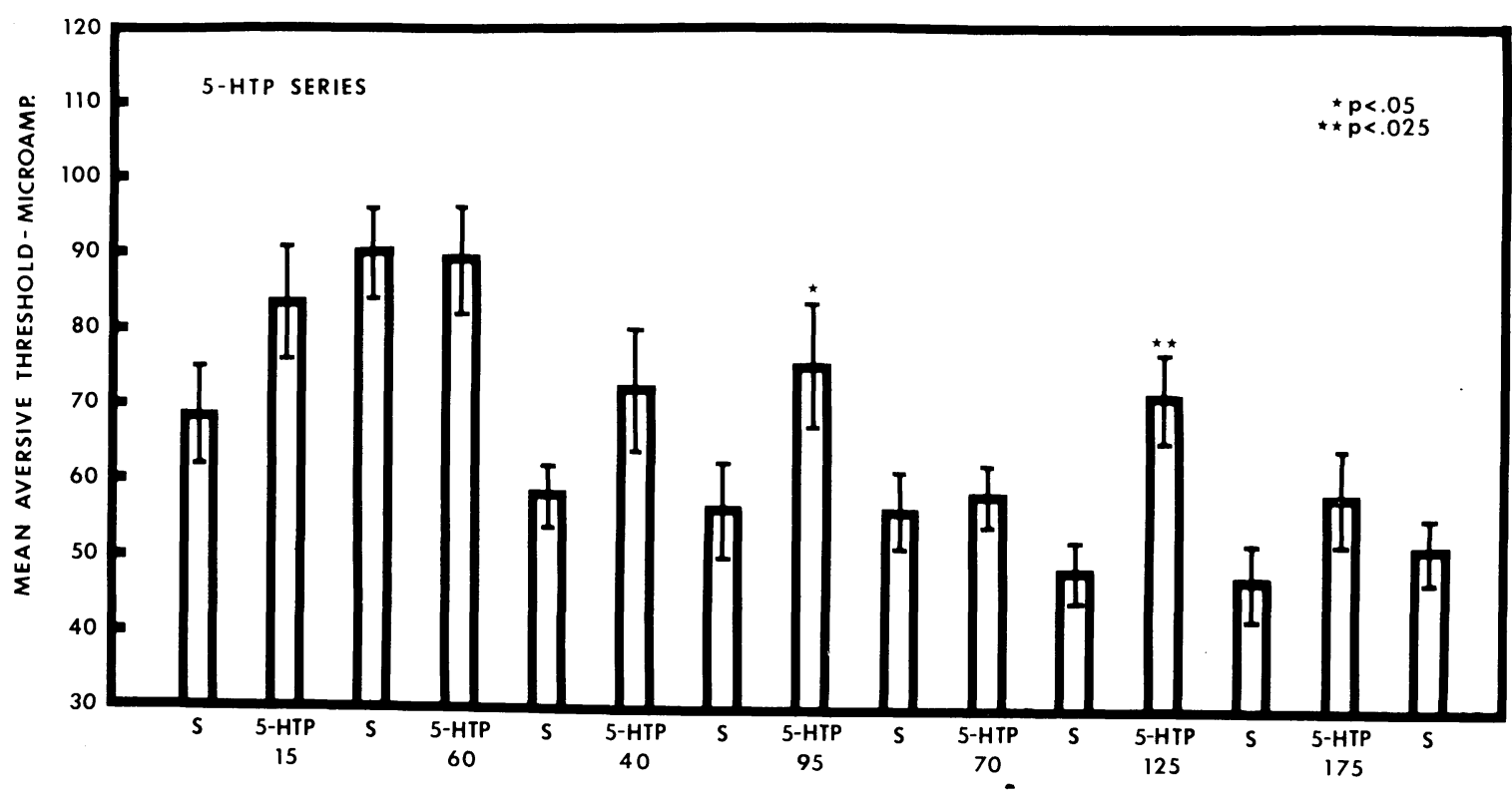

Fig. 1. Mean aversive threshold in microamperes with corresponding standard error of the means for those six animals subjected to various doses of 5-HTP. Each bar represents the mean of three consecutive saline (S) or drug sessions. Probability levels are given for individual $F$ tests comparing the various drug dosages with the preceding saline series. All dosages are given in $\mathrm{mg} / \mathrm{kg}$.

The shock was automatically switched from one side to the other every $5 \mathrm{~m}$ in to insure that each animal sampled all shock intensities even if it failed to make a crossing response during the 10 -min period that each intensity was presented.

The dependent measure consisted of the amount of time in seconds spent on the shock side of the cage for each shock intensity. The aversive threshold was calculated daily for each animal by determining the intensity of shock which an animal avoided $75 \%$ of the time. At subthreshold intensities, the animal, by chance, would spend $50 \%$ of the time on the shock side of the cage. Since time spent on the shock side diminished as the shock intensity increased, the $75 \%$ threshold criteria required a simple interpolation process. The number of crossing responses made during each shock intensity was also recorded for each animal.

After 10 sessions, all animals demonstrated stable threshold values. Animals were then randomly assigned to two separate six-animal drug groups. Each drug was given in several separate doses in consecutive weekly series. No drug was administered for the first 3 days of each weekly series (i.e., Monday-Wednesday) followed by 3 days of a particular drug dosage (i.e., Thursday-Saturday). Animals were not tested on the seventh day of these weekly series.

The two drugs administered in the present study consisted of 5-hydroxy tryp tophan $(15,60,40,70,95,125,175 \mathrm{mg} / \mathrm{kg})$ and p-chlorophenylalanine $(300,200,100,50 \mathrm{mg} / \mathrm{kg})$. The 5 -HTP was dissolved in $.9 \%$ saline and administered in a volume of $1.0 \mathrm{ml} / \mathrm{kg} 1 / 2 \mathrm{~h}$ before threshold testing. Since 5-HTP does not completely dissolve in saline, a small amount of tween 80 was added to make a uniform suspension. P-CPA was prepared in $12.0-\mathrm{ml}$ stock solutions as follows: $1800 \mathrm{mg}$ of $\mathrm{p}$-CPA was dissolved in $4.0 \mathrm{ml}$ of $\mathrm{NaOH}(5 \mathrm{~N})$; the $\mathrm{pH}$ was then adjusted to 2.4 by adding $2.0 \mathrm{ml}$ of $\operatorname{HCL}(5 \mathrm{~N})$; then this final solution was diluted with $.9 \%$ saline to obtain the proper drug concentrations for the various drug dosages. Each dosage of p-CPA was administered in a volume of $2.0 \mathrm{ml} / \mathrm{kg}$ in one injection, $24 \mathrm{~h}$ before the first drug testing session. Thus, p-CPA was given on Wednesdays in one injection immediately af ter the third control session of each weekly series. Drug sessions then followed on
Thursday, Friday, and Saturday. The p-CPA animals received one injection of the control (i.e., no drug) solution ( $\mathrm{pH} 2.4$ ) on Sundays before the three control sessions (i.e., Monday-Wednesday). All injections were given intraperitoneally.

\section{RESULTS}

An analysis of variance (Myers, 1966) performed on the daily thresholds for all doses of p-CPA indicated that no significant differences occurred between control and drug sessions. A similar lack of effect was noted when the number of crossings data were analyzed. Thus, p-CPA in all the doses tested (i.e., 300, 200, 100, $50 \mathrm{mg} / \mathrm{kg}$ ) had no significant effects on the aversive threshold or the number of crossings made in the spatial preference technique.

The mean aversive threshold data for the six animals subjected to the various dosages of 5-HTP are presented in Fig. 1. As Fig. 1 indicates, only the 95- and $125-\mathrm{mg} / \mathrm{kg}$ dosages reliably raised the aversive threshold to moderate levels. The effects noted in this figure were not dose related in that higher doses did not lead to greater increments in the aversive threshold.

Figure 2 presents the mean number of crossing data for those animals subjected to the various dosages of 5-HTP. These data indicated that the middle range of doses (i.e., $60,70,95,125 \mathrm{mg} / \mathrm{kg}$ ) were all able to reliably reduce the number of crossings made, while the extreme doses (i.e., $15,40,175 \mathrm{mg} / \mathrm{kg}$ ) had no effect. Again, the results in Fig. 2 did not appear to reflect a clear dose-response relationship. In addition to the data in Fig. 1, the six animals who received 5-HTP were given 


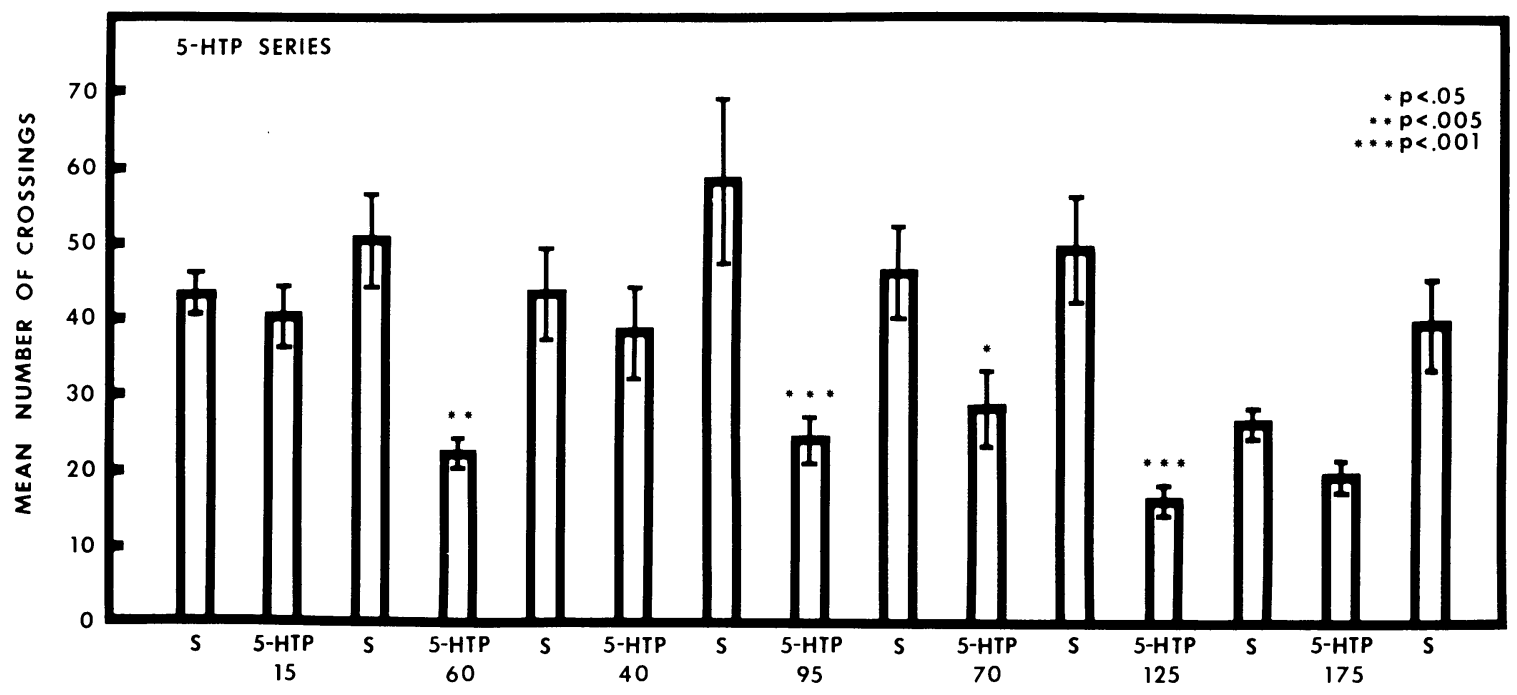

Fig. 2. Mean number of crossing responses with corresponding standard error of the means for those six animals subjected to 5-HTP. Each bar represents the mean of the three consecutive saline (S) or drug sessions. Probability levels are given for individual $\mathrm{F}$ tests comparing the various drug dosages with the preceding saline series. All dosages are given in $\mathrm{mg} / \mathrm{kg}$.

a final test in which they were pretreated with $200 \mathrm{mg} / \mathrm{kg}$ of $\mathrm{p}$-CPA $24 \mathrm{~h}$ before the start of a 3-day drug series, in which they received $125 \mathrm{mg} / \mathrm{kg}$ of $5-\mathrm{HTP}$ $1 / 2 \mathrm{~h}$ before threshold testing: This dosage of $\mathrm{p}$-CPA was able to block the increase in the aversive threshold and the reduction in motor activity noted when 5-HTP $(125 \mathrm{mg} / \mathrm{kg})$ was administered alone.

\section{DISCUSSION}

It is apparent from the above results that reductions in serotonergic activity via the administration of p-CPA do not affect the aversive threshold to electric shock in the rat. Furthermore, the fact that 5-HTP was only able to raise the aversive threshold to moderate levels in a manner that was not dose related, suggests that elevations in serotonergic tone probably do not directly affect pain sensitivity in the rat. The elevations in the aversive threshold noted under 95 and $125 \mathrm{mg} / \mathrm{kg}$ of $5-\mathrm{HTP}$ were in all likelihood due to the reductions in motor activity noted under these dosages (e.g., see Fig. 2). These reductions in motor activity, in turn, could have been produced by one or more of the nonspecific effects of the drug. Intravenous injection of serotonin in man has been reported to produce various sensations including nausea and cramps (Hollander, Michelson, \& Wilkins, 1957). Animals subjected to these effects of the drug could have been sufficiently debilitated to cause enhanced escape latencies and thus produce higher aversive thresholds. To conclude, it would appear that variations in behavior exhibited in the rat in response to alterations in serotonergic tone in aversive test situations are probably not a reflection of a change in the aversive threshold to electric shock. analgesia by drugs affecting adrenergic and tryptaminergic mechanisms. Journal of Pharmacy \& Pharmacology, 1970, 22, mechanism

Geller, I., \& Blum, K. The effects of 5-HTP on para-cholorophenylalanine (p-CPA) attenuation of "conflict" behavior. European Journal of Pharmacology, 1970, 9, 319-324.

Holland er, W., Michelson, A. L., \& Wilkins, R. W. Serotonin and antiserotonins. I. Their circulatory, respiratory and renal effects in man. Circulation, 1957, 16, 246-255.

Houser, V. P., \& Paré, W. P. A method for determining the aversive threshold in the rat using repeated measures: Tests with morphine sulfate. Behavior Research Methods \& Instrum entation, 1972, 4, 135-137.

Houser, V. P., \& Paré, W. P. Measurement of analgesia using a spatial preference test in the rat. Physiology \& Behavior, $1973 a, 10,535-538$.

Houser, V. P., \& Paré, W. P. Analgesic potency of sodium salicy late, indomethacin and chlordiazepoxide as measured by the spatial preference technique in the rat. Psychopharm acologia, 1973b, 32, 121-131.

Lee, J. R., \& Fennessy, M. R. The relationship between morphine analgesia and the levels of biogenic amines in the mouse brain. European Journal of Pharmacology, 1970, 12, 65-70.

Myers, J. L. Fundamentals of experimental design. Boston: Allyn \& Bacon, 1966.

Reus, J. F., Houser, V. P., \& Paré, W. P. An electric ronstant current shock generator for low current levels. Physiology \& Behavior, 1971, 7, 635-637.

Stein, L., Wise, C. D., \& Berger, B. Antianxiety action of benzodiazepines: Decrease in activity of serotonin neurons in the punishment system. In S. Garattini, E. Mussini, and L. O. Randall (Eds.), The benzodiazep ines. New York: Raven Press, 1973.

Tenen, S. S. The effects of p-cholorophenylalanine, a serotonin depletor, on avoidance acquisition, pain sensitivity and related behavior in the rat. Psychopharmacologia, 1967, 10, 204-219.

Tenen, S. S. Antagonism of the analgesic effect of morphine and other drugs by p-chlorophenylalanine, a serotonin depletor. Psychopharmacologia, 1968, 12, 278-286.

\section{REFERENCES}

